\title{
Molecular and morphological characterization of piecemeal degranulation in human neutrophil azurophilic granules
}

\author{
Salahaddin Mahmudi-Azer ${ }^{1 *}$, Peter F Weller ${ }^{2}$, Ann M Dvorak ${ }^{2}$, Redwan Mogbel ${ }^{3}$, Peter D Paré ${ }^{4}$ \\ From Canadian Society of Allergy and Clinical Immunology Annual Scientific Meeting 2010 \\ Victoria, Canada. 3-6 November 2010
}

Mediators pre-stored in neutrophil azurophilic granules are central to the acute inflammatory response and tissue degradation and damage through their proteolytic activity. Different granule populations mobilize and release their content via distinct and hierarchical molecular mechanisms. The molecular mechanisms by which mediators pre-stored in azurophilic granules are mobilized and released to the extracellular space remain largely unknown. We used a number of complementary techniques including; confocal laser scanning microscopy, subcellular fractionation, flow cytometric analyses, Western blot analyses and electron microscopy to examine the ultrastructural and molecular nature of mediator release in neutrophil azurophilic granules. We found that following IL-8 activation, neutrophil azurophilic granules undergo piecemeal degranulation (selective mediator release) leading to altered granule content. Piecemeal degranulation of azurophilic granules is characterized by budding of small secretory vesicles and consequent reduction in granule density. Furthermore, budding of small secretory vesicles and selective mediator mobilization and release from azurophilic granules is associated with reduced localization of CD63, Hck and $\beta$-arrestin-1 to granule membranes and also cell surface upregulation of these molecules. Our study is first to identify piecemeal degranulation as a potential underlying mechanism of mediator release from neutrophil azurophilic granules and supports the involvement of CD63, Hck, and $\beta$-arrestin-1 in this process.

\footnotetext{
* Correspondence: sazer@shaw.ca

'From Department of Medicine, University of Calgary, Alberta, Canada Full list of author information is available at the end of the article
}

\section{Author details}

${ }^{1}$ From Department of Medicine, University of Calgary, Alberta, Canada. ${ }^{2}$ Harvard Thorndike Laboratory and Charles A. Dana Research Institute, Departments of Medicine and Pathology, Beth Israel Deaconess Medical Center, Harvard Medical School, Boston, MA 02215, USA. ${ }^{3}$ Department of Immunology, University of Manitoba, Faculty of Medicine, Winnipeg, Manitoba, Canada. ${ }^{4}$ The James Hogg iCAPTURE Centre, St. Paul's Hospital, Dept. of Medicine, University of British Columbia, Canada.

Published: 4 November 2010

\section{doi:10.1186/1710-1492-6-S2-P20}

Cite this article as: Mahmudi-Azer et al.: Molecular and morphological characterization of piecemeal degranulation in human neutrophil azurophilic granules. Allergy, Asthma \& Clinical Immunology 2010 6(Suppl 2):P20.

Submit your next manuscript to BioMed Central and take full advantage of:

- Convenient online submission

- Thorough peer review

- No space constraints or color figure charges

- Immediate publication on acceptance

- Inclusion in PubMed, CAS, Scopus and Google Scholar

- Research which is freely available for redistribution
Biomed Central 